dar a sociedade a alcançar um futuro no qual todos os produtos tenham ciclos de vida projetados de forma a haver um encadeamento de ciclos que náo produza lixo (por lixo, entenda-se produto secundário inuitil). As maneiras de se dar valor a energia e materiais seráo muito diferentes: cada produto será visto como ingrediente do produto posterior. Todo processo que produza produtos secundários intíteis ou de pouco valor será severamente desvalorizado. Para conseguir controle sobre o ciclo de vida dos materiais, será necessário: uso/reaproveitamento de materiais comerciais; projeto de novos materiais que possam ser indefinidamente reciclados; e processos para fazer novos materiais que náo impliquem rejeitos de produtos danosos para o meio-ambiente.

\title{
A INDÚSTRIA AERoESPACIAL: QUESTÓES ECONÔMICAS, TECNOLÓgICAS E SOCIAIS
}

\author{
GIORGIO E. O. GLACAGLIA \\ (Escola Politécnica da USP, São Paulo, Brasil)
}

\begin{abstract}
principal propósito desta palestra é o de analisar o papel que as atividades aeroespaciais tiveram e têm no desenvolvimento de uma sociedade melhor através da tecnologia. Nossa principal preocupação é nos concentrar na questão básica de quanto e onde uma nação deve investir em tecnologia, tecnologia aeroespacial em particular, e quais devem ser as bases para tais decisóes. A exploraçáo do espaço, como qualquer outra exploraçáo feita pela humanidade, deu à sociedade uma nova perspectiva de si própria e do Universo. Expandimos nosso conhecimento até as fronteiras do Sistema Solar e além delas. Quais são os benefícios dos investimentos feitos no sentido de atingir esses objetivos? Qual é o retorno mensurável? Quais os melhores investimentos que podemos imaginar para suprir nossas necessidades sociais e ampliar nossa compreensão acerca da própria vida?
\end{abstract}




\section{O impacto e o progresso da ciếncia e da tecnologia}

EUA, Europa Ocidental e Oriental investiram bilhóes de dólares no desenvolvimento de programas espaciais. $O$ retorno para a sociedade dos investimentos governamentais é mais evidente nos dois primeiros, devido ao maior papel ali desempenhado pelas companhias $\mathrm{e}$ instituiçóes privadas. É também importante notar que o avanço da ciência se dá através de dois caminhos principais: um, definido por questóes que devem ser respondidas e servem como objetivos básicos, de tal forma que exista um esforço organizado no sentido do desenvolvimento. $O$ melhor exemplo, em época recente, foi a corrida espacial. A respeito do programa espacial norte-americano, V. Siegel, em 1983, escreveu que "não foi por acaso que atingimos nossa atual posição de líderes no espaço. Chegamos até ela porque tivemos a imaginaçáo de sonhar grandes sonhos e a vontade nacional para realizá-los. Chegamos lá porque a associafã̃o com o governo, indústria e universidades, construída através dos anos, criou uma base científica e de alta tecnologia que não perde para ninguém".

O segundo caminho resulta das oportunidades tecnológicas e observacionais, nas quais podem ser identificados grandes pontos de referência, como o telescópio, o microscópio, o computador, o laser, o transistor, todos eles tendo aberto novos domínios em ciência e tecnologia. O primeiro caminho pode certamente ser resultado de um plano oficial governamental de desenvolvimento. $O$ segundo é mais claramente o resultado de trabalho cientifico e tecnológico independente, e isso deve ficar evidente para as instituiçóes que promovem políticas e financiamento para ciência e tecnologia.

\section{Exploração do espaço exterior}

A ciência espacial deu importante contribuiçáo para uma nova era de descoberta, avançando as fronteiras do conhecimento acerca de nosso planeta, do Sistema Solar e do Universo. Satélites descobriram a existência do cinturăo de radiaçáo de Van Allen em torno da Terra e demonstraram que o campo magnético desta é como uma vasta gota cósmica, enformada pelo vento solar. A interação entre esse gás aquecido e eletrificado e o campo magnético explicou os blecautes de rádio, as falhas $\mathrm{em}$ circuitos elétricos, o comportamento errático das bússolas e as auroras. Os satélites mostraram que a atmosfera superior náo é uma região calma, como se pensava antes. Na verdade, ela se altera radicalmente com as erupçóes solares, o ciclo solar de 11 anos e o período solar de rotação de 27 dias. 
Eles descobriram que tanto o vento solar quanto o campo magnético solar atingem bilhóes de quilômetros além da superfície do Sol. Os observatórios orbitais mudaram muito nossos pontos de vista sobre 0 Sol e sobre o Universo, nunca antes vistos sem o filtro atmosférico: as fontes de raios-X são abundantes, indicando que poderosos processos dominam a evolução do Universo. A natureza dos planetas interiores e exteriores sofreu dramática mudança com respeito às nossas velhas observaçóes e teorias: a Lua é mais agressiva para a vida do que jamais se supôs; a camada de nuvens que envolve Vênus é primariamente composta de gotículas de ácido sulfúrico em atmosfera de quase $100 \%$ de dióxido de carbono, com uma pressão à superfície quase 100 vezes maior que a experimentada sobre a Terra, e uma temperatura superficial de mais de $480^{\circ} \mathrm{C}$, resultado de efeito estufa, o processo físico que está pouco a pouco aumentando a temperatura de nosso próprio planeta. Marte náo tem canais, mas possui certamente um sistema aluvial impressionantemente extenso, indicando que muito antes em sua história a água já correu pela superfície, hoje desprovida de qualquer sinal observável de vida. É possível que tanto Marte quanto Vênus tenham tido um meio-ambiente ameno no passado distante, mas náo somos capazes de detectar qualquer traço de vida nessa história passada. Descoberta estranha foi a inexistência de campos magnéticos em torno desses planetas. Outro achado inesperado foi um fraco campo magnético em torno de Mercúrio. Tudo isso se opóe a teorias bem-estabelecidas. Sabemos agora que os fortes campos magnéticos de Júpiter e Saturno são provavelmente devidos a hidrogênio metálico líquido em rápida rotação e que tal estado físico do hidrogênio seria impossível de ser duplicado na Terra. Mostrou-se que esses planetas têm mais satélites do que antes havia sido observado. Anéis, como os de Saturno, foram descobertos em Júpiter e Urano. Satélites dos planetas gigantes foram fotografados e sua superfície mostrou vistas nunca antes imaginadas. Muitos dos satélites jovianos têm gelo na superfície e abaixo dela. Atividade vulcânica foi observada em Io, um dos satélites de Júpiter. Mostrou-se também que os anéis de Saturno são compostos principalmente por gelo de água, bem como seus satélites, exceto o exterior, Febe, possivelmente, um asteróide capturado. Titá, o grande satélite saturnino, composto de rochas e água, que se pensava ser o maior do Sistema Solar, mostrou-se menor que o joviano Ganimedes. Ao lado de Calisto, esses três satélites são maiores que Mercúrio e Plutáo. Todos esses achados mostraram que a água é bastante abundante no Sistema Solar. Mas Titá mostrou o fato incrível de ter uma atmosfera de nitrogênio, metano, etano, acetileno, etileno, hidrogênio, cianeto e muitos outros gases orgânicos. Teoriza-se que essa era mais ou menos a composiçáo da atmosfera terrestre nos primeiros 
estágios de sua evolução. Com alguma imaginação, pode-se justificar o financiamento desses achados cósmicos como necessidade para a construçáo de uma sociedade melhor, através da ciência.

\section{Os objetivos da exploração do espaço próximo à Terra}

Os satélites construídos atualmente são uma simples melhoria dos que eram construídos vinte anos atrás. $O$ mesmo vale para os motores de foguetes e de avióes. Uma nova descontinuidade no progresso tecnológico virá apenas quando mudanças de larga escala forem introduzidas na eficiência e nos custos desses artefatos: novos motores e fontes de energia, tecnologia mais segura e limpa. Uma viagem de São Paulo a Lisboa ou Miami não deverá durar mais que um par de horas, ao passo que uma viagem para Marte será feita por uma rota mais curta que a ditada somente pela Lei da Gravitação de Newton. Como isso vai acontecer é impossível de dizer. No passado, as guerras estavam entre os maiores catalisadores das grandes descobertas: jatos puros, energia atômica, mísseis capazes de lançar uma tripulaçáo à Lua, mas também capazes de carregar ogivas por milhares de milhas. Passamos agora por uma era, no geral, calma e observamos muito mais preocupaçáo com o homem e com sua sobrevivência: ecologia, habitabilidade, conservaçáo, reciclagem e, em menor medida, fome, são usadas diariamente por cientistas e políticos. Devemos concentrar nossos recursos apenas na soluçáo desses problemas, usando a tecnologia já disponível? Devemos abandonar a pesquisa $\mathrm{em}$ aeroespaço? Por que devemos ir de uma cidade a outra em cada vez menor tempo? Por que devemos ir até a Lua, aos planetas e além? Por que precisamos de um telefone celular se podemos usar uma linha comum? Por que preciso de um PC e de um software inteligente para escrever este artigo? Essas questóes sáo difíceis de responder, especialmente quando olhamos para crianças morrendo de fome na Etiópia e, entre nós, aqui em São Paulo.

Podemos tentar algumas respostas comuns para as questóes acima. Todos sabemos quais os objetivos declarados das atividades espaciais. Muito da exploração em torno da Terra tem aplicações claras: estudo sobre o ozônio, ventos, cobertura de nuvens, taxas de radiaçáo, precipitaçáo e vapor de água, temperatura à superfície do mar, ventos de superfície, altura de ondas e gelo marítimo, cobertura de gelo, vegetaçáo, umidade do solo, temperatura da terra, insolaçăo, vulcóes e queimadas, busca e salvamento, coleta de dados, colocação de plataformas, satélites de comunicaçáo de órbita baixa para receptores pequenos móveis em áreas remotas, nas quais é difícil estabelecer comunicação por 
rede, predição do clima, deteç̧ão de composiçăo e poluição, topografia oceânica, correntes oceânicas, movimentos continentais e da crosta, topografia de larga escala, uso e abuso da terra, pesquisa da flora e da agricultura, motores, baterias, sistemas de comunicação, imagens, reconhecimento de padrōes, desenvolvimento de materiais, processos de sol$\mathrm{da}$, bioquímica e biologia em ambiente de gravidade zero. $\mathrm{O}$ sistema terrestre pode atualmente ser observado em seus mais diferentes aspectos, pois agora vemos melhor que jamais antes as relaçóes múltiplas entre oceanos, terra e fenômenos atmosféricos. $O$ fenômeno oceano-atmosférico chamado $E l N i n ̃ o$, por exemplo, pode ser causado por atividade vulcânica subaquática no Pacífico, a qual é gerada por fluxo de magma ao longo de uma crista oceânica, relacionada à tectônica de placas, esta relacionada ao calor interno e forças de maré sobre as quais Sol e Lua têm papel importante. Os benefícios tecnológicos para a sociedade advindos desses tipos de atividade espacial sáo também bastante conhecidos: microprocessadores, hardwaræe software de comunicaçóes, materiais, produção automatizada e sistemas de gerenciamento, melhor predição do clima, pesquisa e controle da terra a baixo custo, desenvolvimento de inteligência artificial, entre incontáveis outras açōes. Muitas destas já estão gerando atividade comercial internacional.

\section{Ciência, tecnologia e sociedade: os países em desenvolvimento}

Nós, nos países em desenvolvimento, temos de decidir se queremos usar nossos escassos recursos nas fronteiras da ciência e tecnologia, ou concentrar esforços nas necessidades básicas de nosso povo. Quando colegas europeus e norte-americanos me perguntaram por que motivo năo estávamos cuidando da saúde, educaçăo e alimentaçăo de nosso povo fiz notar que nossa economia é comparável à de um pequeno país europeu, ao passo que nossa extensáo territorial e populaçáo assemelham-se às dos EUA. Historicamente, nossa sociedade foi construída à base de agricultura de baixa tecnologia e nossa terra sempre esteve concentrada nas mäos de poucas pessoas, o que é, parcialmente, conseqüência de um sistema colonial feroz e predatório. Como exemplo dos investimentos necessários, tomemos a cidade de Săo Paulo, onde vive uma populaçáo de 15 milhốes de habitantes (cidade mais área metropolitana). Se quiséssemos ter um meio-ambiente decente, incluindo tratamento de esgotos, precisaríamos, só nesse setor, investir muitos anos do orçamento total do Estado, não apenas da cidade. Vejam agora o problema educacional: com dezenas de milhóes de crianças em idade escolar, precisamos de enorme montante de dinheiro para construir salas de aula, preparar professores, produzir livros e tudo o mais que é necessário 
para se ter um sistema educacional decente em funcionamento.

Investimos, nas últimas décadas, bilhóes de dólares na criaçăo de infra-estrutura para um desenvolvimento agrícola e industrial: auto-estradas, usinas hidrelétricas, sistemas de telecomunicaçóes, produçâo e distribuição de petróleo, instalaçóes portuárias, aeroportos, sistemas de navegaçáo fluvial, hospitais e postos de saúde. Além disso, desenvolvemos uma indústria de boa qualidade que produz, essencialmente, tudo de que precisa uma sociedade moderna: cimento, aço, tecidos, plásticos, mobiliário, ferramentas, navios, satélites, aeronaves, vagóes para trens e metrôs, carros e caminhóes, enfim, qualquer coisa. Enquanto isso, as taxas de juros cobradas pelos agentes financeiros internacionais cresceram até atingir recordes históricos, pressionando nossos governos econômica e politicamente. Năo fosse pelos generosos empréstimos tomados pelos países em desenvolvimento, a fantástica quantidade de petrodólares que pinga nessas instituiçóes năo teria onde ser investida. Ainda assim, nossa economia, mesmo considerando nossa histórica incompetência em planejar e administrar, é muitíssimo pequena para suprir todas as nossas necessidades, devido, em parte, ao crescimento populacional descontrolado. Esse problema é, de fato, comum a muitos países grandes com pequena economia. Nosso produto nacional bruto, dividido pela populaçăo, dá menos de quatro mil dólares per capita ao ano. Precisamos, assim, ou aumentar o numerador ou diminuir o denominador. As duas operaçóes são difíceis de realizar. Lutamos para investir o que é claramente insuficiente para seguir o progresso tecnológico dos países grandes. E quanto mais progredimos, mais para trás ficamos.

Como consultor do Instituto Nacional de Pesquisas Espaciais fui, em alguma medida, responsável pelo desenvolvimento de uma equipe técnica de alto nível especializada em satélites artificiais, o que começou há 18 anos, em 1975. A cooperação com a ESA - a Agência Espacial Européia -, levou à nossa atual capacidade para projetar e construir bons satélites para coleta de dados, sensoriamento remoto e, em futuro próximo, comunicaçóes. Nosso investimento total ficou bem abaixo de um bilhăo de dólares, quantia ridícula quando comparada aos investimentos feitos na Europa (tanto ocidental quanto oriental) e nos EUA. Por exemplo, no período de 1987 a 1989 , os investimentos anuais no INPE, exceto salários, foram de cerca de US\$ 50 milhóes, caindo pela metade desde então. Apesar disso, o nível de empregos foi mantido, de 1.593 empregados em 1987, para 1.384, em 1991. Deve-se notar, entretanto, o que está acontecendo entre nós, a exemplo do que ocorre em outros países em desenvolvimento: 0 orçamento alocado para salários, no mesmo período, caiu de US\$ 43 milhóes para pouco mais de US\$ 
17 milhóes, ou seja, os salários perderam rapidamente valor real.

Situação semelhante pode ser vista na indústria aeroespacial brasileira. A despeito de tudo, observamos que algumas indústrias e firmas de engenharia privadas adquiriram tecnologia moderna para projeto e construção. Como isso irá progredir é difícil dizer. Estamos tentando organizar a Agência Espacial Nacional, a qual esperamos servirá para melhorar o planejamento da pesquisa e exploração espacial para o benefício de todos e não apenas de uma minoria. Isso é algo que tem sido difícil de implementar nos países em desenvolvimento, mas que precisa ser superado. Dessa forma, para sobrevivermos como naçáo e país, nossa tomada de decisão deverá se dar na direçáo da ciência e da tecnologia para benefício social. O desenvolvimento de nossa indústria espacial deve se conformar a esse objetivo básico: não existe espaço para tecnologias adquiridas na forma de pacotes fechados, já que assim não há transferência nem ganho. Isso, é claro, não pode ser um simples exercício de nacionalismo estúpido, mas um exercício de investimentos planejados e judiciosos para as geraçóes futuras. E esse procedimento pressupóe uma sociedade democrática, na qual as decisóes sejam tomadas pelo povo ou por seus legítimos representantes.

Para não falar apenas de espaço, direi álguma coisa sobre a indústria aeroespacial como um todo: mesmo as naçóes mais ricas lutam hoje por melhóres aeronaves, mais seguras e econômicas, em um cenário economicamente ruim. A situaçăo atual, no Brasil, é mais ou menos dramática: temós tido considerável sucesso em projetar e construir pequenas aeronaves e desenvolvemos um grande parque industrial aeroespacial em torno de São José dos Campos, perto de Sáo Paulo. Em algumás dessas indústrias, ainda encontramos esforços isolados de sobrevivência. Hoje, a força de trabalho, naquela regiâo, foi reduzida a menos da metade do que era há poucos anos e muitos engenheiros e operários foram demitidos. Dessa forma, perdemos importante semente para o desenvolvimento de uma boa indústria aeroespacial local e nossa decisão deve ser a de salvá-la. A principal razáo é que através dessa indústria, tanto de espaço como de aeronáutica, podemos fixar padróes de qualidade que, de outra forma, não seriam financeiramente viáveis. Precisamos de tecnologia aeroespacial para que nossa indústria seja competitiva nos mercados internacionais. Esse esforço deve ser auto-sustentado e não deve drenar recursos do já parco orçamento governámental; pelo contrário, deve somar à economia. Assim, idealmente, precisamos desenvolver uma indústria bi-tech para competir, para vender, para lúcrar, para capitalizar e' construir ùm futuro mais rico para nossa nação. Através desse tipo de esforço, seremos capazes de quebrar o ciclo vicioso da pobreza e termos uma sociedade sustentável. 


\section{Qual deve ser nossa decisão?}

Vou citar um artigo recente escrito pela deputada federal Irma Passoni acerca do hiato científico e social existente no Brasil e em outros países em desenvolvimento. "As mudanças que ocorrem no panorama internacional mostram que mesmo as naçóes mais poderosas não têm garantidas as condiçóes para manutençăo de seu progresso. Năo basta ter companhias e mercados, já que ambos podem ser enfraquecidos e conquistados por sistemas que mais eficientemente transformem ciência e tecnologia em produtos. Da mesma forma que o acesso à ciência e à tecnologia é importante mas náo suficiente para liderar em termos econômicos, a eliminação do hiato náo pode ser obtida por simples acesso a técnicas e produtos modernos, pois estes podem não ter qualquer relação com nossa realidade. Tê-los não é o mesmo que entendề-los ou deles fazer um uso correto. $O$ desenvolvimento industrial no Brasil e o papel quase sempre secundário desempenhado pelo sistema científico e tecnológico mostram que a produção ou utilizaçáo de bens que simbolizam progresso nem sempre andam de mãos dadas com o conhecimento necessário para garantir progresso efetivo e permanente. ... Seja qual for a estratégia (para a eliminação do hiato), ela deve priorizar políticas que incluam esses brasileiros (no passado condenados a ficar de fora de qualquer tipo de benefício), dando-lhes oportunidades de vida e de trabalho, bem como acesso aos produtos que satisfaçam suas necessidades e desejos ". Enfrentamos a difícil questáo de como financiar vários programas nacionais essenciais e vitais, quando o orçamento disponível dá para apenas uns poucos. O que Irma Passoni afirma é que as prioridades devem ser revisadas em termos de necessidades nacionais globais e nảo em termos de interesses corporativos, associados a quaisquer grupos, sejam estes políticos, sociais ou econômicos.

Como mencionado anteriormente, se, no passado, umas poucas naçóes poderosas fizeram do objetivo nacional a exploraçăo do espaço, essa exploraçáo náo foi necessariamente boa para todos os setores da sociedade. Os melhores resultados foram obtidos por naçóes com governos democráticos liberais, nas quais a livre empresa popularizou a bi-tech envolvida nas ciências e tecnologias do espaço. Deveria entáo ser possível estabelecer planejamento e previsăo, se tais investimentos fossem considerados úteis para todos os cidadáos de boa vontade. Como exemplo simples, considerem as aplicaçōes agrícolas dos satélites de sensoriamento terrestre: $o$ objetivo deve ser $o$ de aumentar a produtividade da terra através de melhor previsáo, resultando não apenas em maiores lucros para poucos, mas, também, e acima de tudo, bens de baixo preço. Um sistema de comunicação móvel deve servir às áreas remotas, não 
para ser usado por prazer ou luxo, mas para apoiar pessoas que trabalham em tais lugares e que têm necessidades urgentes de comunicaçáo para garantir sua sobrevivência. Plataformas de coleta de dados oceânicos devem ser usadas, por exemplo, para melhor detectar cardumes, não apenas para aumentar o lucro das companhias pesqueiras, mas para baixar os custos e, assim, os preços dos produtos. 